\title{
Brain Dominance And Speaking Strategy Use of Iranian EFL Learners
}

\author{
Nastaran Mireskandari \\ E-mail: mireskandarin@yahoo.com \\ Sepideh Alavi (Corresponding author) \\ School of Literature and Humanities, Shiraz University, Iran \\ E-mail: salavi@rose.shirazu.ac.ir
}

Received: 05-09- 2014

Published: 01-05- 2015
Accepted: 06-12- 2014

doi:10.7575/aiac.ijalel.v.4n.3p.72
Advance Access Published: December 2014

URL: http://dx.doi.org/10.7575/aiac.ijalel.v.4n.3p.72

\begin{abstract}
The present study investigated the effect of brain dominance on the use of Language learning speaking strategies. One hundred forty two undergraduate students of Shiraz University, Iran, participated in this study. The Hemispheric Dominance Test (HDT) was employed to categorize participants as right-, left- and whole-brain dominant, and a Speaking Strategy Questionnaire was administered to evaluate their use of speaking strategies. The results were analyzed using a one-way between groups analysis of variance (ANOVA) to investigate whether there were any significant differences between the three brain dominant groups in their overall use of speaking strategies. A MANOVA was also run to investigate whether the groups had preferences regarding the use of any particular strategy type. Results indicated a statistically significant difference between the whole brain dominant participants and both left brain and right brain dominant learners for using compensation speaking strategies. To teach and learn more effectively, instructors and learners need to better understand and appreciate individual differences and how they can affect the learning process. They could find ways to combine activities that accommodate both left and right brain learners, employing not only the usual linear, verbal model, but also the active, image-rich, visuo-spatial models so that learners would be able to use both hemispheres.
\end{abstract}

Keywords: Brain dominance, language proficiency, speaking strategies, listening strategies

\section{Introduction}

Successful foreign language learners try to compensate and reduce the language difficulties and deficiencies faced during their communication in English in order to facilitate linguistic interaction. They use conscious strategies to enhance learning or use of the target language, and consequently try to achieve communicative competence. Such learning strategies have a strong potential for enhancing the development of English as a Foreign Language (EFL) oral skills (O'Malley, Chamot, Stewner-Mazanares, Kupper, \& Russo, 1985). Research suggests that learners can improve their communicative language ability by using and learning certain strategies that help them to become independent learners (Nakatani, 2010). The appropriate and frequent use of such strategies is associated with achievement and proficiency (Oxford, 2003) and more independence and autonomy (O’Malley \& Chamot, 1990).

Language learning strategies have been widely discussed in language learning research. However, in recent years more attention has been given to exploring the factors which may affect the choice of these strategies among learners. Among these factors learning style have shown a strong effect on the learners' application of different types of strategies (Vandergrift, 1997). Wang (2008) defined learning style as individual's characteristics and natural, habitual, and preferred way(s) of absorbing, processing, organizing and retaining new information and skills. In the literature, various learning styles and learning style models have been defined. The differences among definitions and models evolve from the fact that learning is achieved at different dimensions and that scholars define learning styles by focusing on different aspects (Yilmaz-Soylu \& Akkoyunlu, 2002). One such dimension in the learning style continuum applicable to second/foreign language learning and teaching is left- and right-brain functioning (Brown, 2007). Dulger (2012) mentioned that brain hemisphericity is closely linked to learning styles, which are influential on individuals' use of learning strategies. Gibson (2002) suggested that learning strategies of children differ from each other in terms of brain dominance and that brain dominance has certain effects on their learning and communication. That is to say, individuals use different sides of their brains to process different kinds of information. Investigation into the possible relationship between brain dominance and language learning strategies, therefore, appears to be a significant step to be taken in language learning research. Since one hemisphere is relatively more skilled than the other in processing different kinds of tasks, one would expect the nature of the task to engage the hemisphere specialized for that task (Alptekin \& Atakan, 1990). In other words, once a relationship between brain dominance and strategy use is recognized, language learning strategies can be taught to learners based on their brain dominance types (Dulger, 2012). Although several studies have been conducted on LLSs, there seems to be limited research on speaking strategies. Although speaking is one of the 
most ignored skills in EFL/ESL research, for many learners, it is one of the most important goals and there is much interest in learning it, especially in the EFL context of Iran where lack of contact with native speakers of English has made the learning process of this skill difficult. Moreover; there is a scarcity of studies on the effects of different factors on the use of speaking strategies. Especially to the authors' knowledge, no study has investigated the possible relationships between speaking strategy use and brain dominance, more studies seem to be needed to discover the nature and types of relationships that might exist between the use of speaking strategies and hemisphericity in a language learning context.

To fill these gaps, the present study aims to investigate the effect of brain dominance on speaking strategy use of EFL students. The following sections attempt to define briefly each of these constructs and to report the findings of previous studies related to each.

\subsection{Speaking Strategies}

Communication strategies (CSs) were first defined by Seliknker (1972), as “a by-product of the learners' attempt to express meaning in spontaneous speech with their limited target language system". CSs have also been referred to by Paribakht (1985) as speakers' solutions to their communication problems. Richards, Platt and Platt (1985, p. 204) also define them as "those devices to which EFL students resort when confronting a communicative problem in their English conversation, in both spontaneous and non-spontaneous speaking, and also those by which a person can use a language".

To understand the concept of speaking strategies, researchers have studied them from the psychological processing perspective rather than surface linguistic forms (Dorney \& Scott, 1997), focusing more on individual differences and looking for areas where these individual differences relate to differences in their patterns of CS use (Littlemore, 2001). The advantages of such approach are helping researchers recognize why different types of learners tend to use particular CSs more than others and why some learners are more flexible than others in their use of CSs.

On the other hand, to gain optimum perceptive on the types of strategies used by speakers in communication, researchers have sought ways of classifying them and have proposed communication strategy inventories that measure the learners' use of communication or speaking strategies (Huang \& Van Naerssen, 1987; Nakatani, 2006; Politzer, 1983; Politzer \& Mcgroarty, 1985; Riazi \& Khodadai, 2007).

Of particular interest to the authors of this paper is Riazi and Khodadadi's (2007) inventory which was a modified version of Ehrman and Oxford (1990), tailored to fit the characteristics of Iranian English language learners. The underlying traits of this questionnaire were meta-cognitive, cognitive, memory compensation, social and affective strategies. Metacognitive strategies include centering one's learning such as paying attention, overviewing and linking to already known material, and delaying speech production to focus on listening, arranging and planning one's learning and evaluating learning via self-monitoring and self-evaluating. Cognitive strategies include repeating, practicing with sounds, recognizing and using formulas and patterns and recombining, receiving and sending messages through getting the idea quickly and using resources for receiving and sending messages, analyzing and reasoning through deductive reasoning, translating and transferring, and creating a structure for input and output. Memory strategies consist of creating linkage, applying images and sounds, structural reviewing and employing action. Compensation strategies comprise of guessing intelligently through using linguistic or other clues, overcoming limitations in speaking through switching to the mother tongue, using mime or gesture and circumlocution or synonym, avoiding communication partially or totally, and adjusting or approximating the message. Social strategies include asking questions for clarification, verification or correction, and cooperating and empathizing with others. Finally, affective strategies consist of lowering one's anxiety through progressive relaxation, deep breathing or mediation and encouraging oneself through positive statement and rewarding.

\subsection{Factors Affecting Speaking Strategies}

Knowledge about the variables influencing the use of communication strategies and their communicative effects has implications for second/foreign language teaching, because the choice of certain communication strategies can either influence or be influenced by various factors. Some studies have examined the effect of variables such as motivation, attitude, gender, level of proficiency, and context of speaking strategies (Chen, 1990; Huang, 2010; Faerch \& Kasper, 1983; Riazi \& Khodadadi, 2007; Sedaghat, 2001; Soodbakhsh, 2009). Others, such as Afsarnia (1999), Bialystok and Fröhlich (1980), Chen (1990), Green and Oxford (1995) and Paribakht (1985), provided evidence of a relationship between the learner's proficiency and their choice of specific CS types.

Bialystock and Frohlich (1980) investigated the conditions for the selection of certain communication strategies in terms of the inferencing ability of the learner, features of the communicative situation (task requirements) and formal proficiency level. They found that once learners reached a certain level of proficiency, inferencing ability determines strategy selection and use. Strategy choice was also found to be highly contextual.

Despite adopting different analytical frameworks and methodological designs, Paribakht (1985) and Chen (1990) obtained similar results and provided further support for the hypothesis that CS use correlates with proficiency both in terms of frequency and choice. However, Oxford and Ehrman (1995) revealed a low correlation between cognitive strategy use and language proficiency and no correlation between proficiency level and other types of strategies.

Littlemore (2001) examined the relationship between holistic/analytic cognitive style and different communication strategies. The results showed that while analytic students preferred strategies that were based on individual features of 
the item, holistic students employed strategies that involved comparison. The findings suggest that communication strategy usage could be partially related to cognitive style.

Although it is intuitively appealing to hypothesize a close relationship between strategy choice and personality traits, little work has been done to study the effect of these traits on the choice and use of language learning strategies. One such trait, which is of interest to the authors of the present paper, is hemisphericity or brain dominance.

\section{3 learning Style/ Hemisphericity and Language Learning Strategy Use}

In the TEFL research domain, learning styles and learning strategy use have been widely integrated (Jie \& Xiaoqing, 2006; Keith, 2010; Lee, 2010; Oxford, 1990; Wong \& Nunan, 2011) and due to their importance in the language learning process, revealing the connections between them can be of great benefit for the learners, teachers and researchers (Cesur \& Fer, 2011). However, few studies have tried to bridge the LLS and LS gap and find the relationship between the two. Among these studies, because of conceptual and methodological differences in the way these studies were conducted, the results of these studies have been somehow inconsistent. Some researchers have reported strong relationships between strategies a learner consciously employs in language learning and their learning styles (Dulger, 2012; Gibson, 2002; Jie and Xiaoqing, 2006; Sabatin, 2012; Selime, 2003; Shi, 2011), while others reported no or moderate relationships between LLS use and LSs (Alavi and Mireskandari, 2014; Jhaish, 2010; Kucuk, 2012; Nikoopour and Farsani, 2010; Shih and Gamon, 2003). In sum, these studies have worked on a different continuum of learning style and few of them have worked on the continuum of hemisphericity. Moreover, most of these studies have worked on language learning strategy in general and not on the strategies related to specific skill such as speaking. Since the relation between speaking strategies and learning style is one of the least examined areas, particularly when it comes to the relationship between learning style categories such as hemisphericity, more research is needed to discover the nature and types of relationships that might exist between the two in different contexts.

\subsection{Hemisphericity}

The term hemisphericity is used to characterize a person's inclination to rely on one brain hemisphere more than the other, regardless of the cognitive nature of task demands (Alptekin \& Atakan, 1990). Although individuals have the capacity to use both hemispheres of their brain, based on the individuals' dominance one hemisphere may take the lead (Leng \& Hoo 1997). Although individuals prefer either right- or -left brain dominance in processing a certain piece of information, some can be whole brain dominant and depend equally on both hemispheres which can bring some advantages on the part of the learner in instructional processes (Dulger, 2012).

Studies on brain hemisphericity (Beck, 2001; Dulger, 2012) have shown that the left-right mode preference determines the way a student receives information. These findings also reveal that students tend to reach higher levels of achievement when they are taught in ways that are compatible with their right-left mode tendencies. Gibson (2002) proposed that learning strategies of children differ from each other in terms of brain dominance and that brain dominance has certain effects on their learning and communication; in other words; individuals use different sides of their brains to process different kinds of information. It must be noted that, although it is believed that each individual relies on one half of the brain more than the other, the two hemispheres are not completely independent, but are connected through fibers (corpus callosum) and work together. Most of the time, however, one is more involved in particular mental functions than the other (Dulger, 2012).

In the realm of language learning, very few studies with contradictory results have been done in the area of brain hemispheres and their effect on language learning. Among these studies, Alptekin and Atakan (1990) and Tendero (2008) revealed no significant relationships between second language achievement and hemisphericity. On the contrary, Oflaz (2011) and Tufekci and Demirel (2008) investigated the effects of right and left brain dominance on students' academic achievement and learning English and found significant differences between the performances of right and left brain students on tests of English.

Very few studies have investigated the relationship between learning strategy use and hemisphericity. Dulger (2012), Gibson (2002) and Sabatin (2012) suggested that learning strategies of children differ with brain dominance and that brain dominance had certain effects on their learning and communication. Contradictory results were, however, obtained by Alavi and Mireskandari (2014), who investigated the pattern of hemisphericity of their ESL students and how it was related to their use of second language listening comprehension strategies. Their results showed no significant relationships between brain dominance and listening strategy use. While the above studies have addressed the relationship between hemisphericity and general language learning strategy use, no other work has specifically tackled the issue of speaking strategies. Hence, more research seems to be needed to discover the nature and types of relationships that might exist between the use of speaking strategies and hemisphericity in a language learning context.

In sum, investigation into the probable relationship between brain dominance and LLSs appears to be a noteworthy step to be taken in language learning research. Once a relationship (or lack of one) between brain dominance and strategy use is recognized, steps can be taken to help improve learning. Due to the great importance of speaking and also brain dominance, the present study aims to investigate the effect of brain dominance on speaking use of EFL students by finding out if any significant differences existed between left-, right-, and whole- brain dominant EFL students in their use of speaking

The study gains significance in that it helps researchers understand how factors such as brain dominance patterns might affect student performances through the use of special speaking strategies. If such relationship exists, students can be taught to compensate for their learning shortages by employing learning strategies suited to their brain dominance 
(Wong \& Nunan, 2011). This study might also be useful to materials producers and curriculum developers by knowing that students with different preferences and tendencies might employ different types or amounts of LLSs, so they can include a variety of speaking tasks in course books to accommodate different brain dominance preferences.

\subsection{Objectives of the Study}

Due to the great importance of speaking and also brain dominance, the present study aims to investigate the effect of brain dominance on speaking strategy use of EFL students. One research questions were thus put forward:

1. Is there any significant difference between left-, right-, and whole- brain dominant EFL students in their use of speaking strategies?

\section{Methods}

\subsection{Participants}

Initially, one hundred and seventy five undergraduate students majoring in English Language and Literature in the department of Foreign Languages and Linguistics of Shiraz University, based on accidental sampling, participated in this study. However, some were excluded from the data analyses because of their incomplete responses to the questionnaires. Since left handed and right handed students are shown to exhibit totally different patterns of lateralization of cognitive functions and certain aspects of LLSs use (Gholami Mehrdad \& Ahghar, 2011; Tremblay, Monetta, \& Joanette, 2004) left-handed students were also excluded from the study. Consequently, the final sample consisted of 142 male and female participants whose age ranged from 18 to 45 .

\subsection{Instruments}

In this study, two questionnaires were used to investigate the relationship between brain dominance and speaking strategy use of language learners. The Hemispheric Dominance Test (HDT) was employed to evaluate the students' brain dominance patterns. A Speaking Strategy Questionnaire was also used to investigate students' speaking strategies. These questionnaires were the most comprehensive in what they intended to measure and were highly related to the purposes of the present study.

\subsubsection{Hemispheric Dominance Test (HDT)}

The Hemispheric Dominance Test (HDT), a modification of Davis et al. (1994) Brain Dominance Inventory, is a 40 item questionnaire with three multiple-choice alternatives $(a, b, c)$ for each item, which was applied to determine the participants' brain dominance in information processing. To classify students into groups, first, the number of "a", "b", and "c"s in the questionnaire should be counted separately. Then, the total of all "a" scores should be subtracted from all "b" scores. Finally, if the "c" score is 17 or higher, the "b" minus "a" score should be divided by three, and rounded up to the nearest number. Consequently, all who got negative scores were considered left brain dominant. Those of positive scores were assigned to right brain dominant group, and those who got zeroes were classified as whole brainers.

\subsubsection{Speaking Strategy Questionnaire}

The Speaking Strategy Questionnaire is a 38 Likert scale item questionnaire based on O'Malley et al. (1985), Huang and Naerssen (1987), and Oxford (1990). It includes four major categories, Metacognitive strategies (17 items), Cognitive (8 items), Memory and Social/Affective ( 8 items) and Compensation strategies (5 items). The answers to the items range from "never" to "very often". Participants were to choose the answer best fit to their habits. The maximum possible score for strategies in this questionnaire were 85 for Metacognitive strategies, 40 for Cognitive strategies, 40 for Memory and Social/Affective strategies and 25 for Compensatory strategies. In order to reduce any kind of misinterpretation on the part of the participants, the translated version of this questionnaire (Souzandehfar, 2009) was used. The reliability of the Persian version was obtained by calculating Cronbach's Alpha and the index obtained was 0.77 .

\subsection{Data Collection Procedure}

The two questionnaires were given to the students to determine their brain dominance preference and to identify their speaking strategy use. Clear instructions on how to fill out the questionnaires were given to students. One of the researchers was present at the data collection session to give explanations and answer questions. Participants were given enough time to answer the questionnaires carefully, patiently and honestly. Confidentiality was ensured and emphasized during each session.

\section{Results}

\subsection{The Effect of Brain Dominance on Speaking Strategy Use}

A one-way between groups ANOVA was conducted to find out possible differences between the participants of each hemisphericity group and their overall speaking strategy (SS) use. Table 1 summarizes the results.

Table 1. ANOVA for overall SS use by left brained, right brained and whole brained learners

\begin{tabular}{llllll}
\hline & Sum of Squares & df & Mean Square & F & Sig. \\
\hline Between Groups & .151 & 2 & .076 & .632 & .533 \\
Within Groups & 16.631 & 139 & .120 & & \\
Total & 16.782 & 141 & & & \\
\hline
\end{tabular}


The above table indicates that the mean difference between the SS use of the three groups was not significant $(\mathrm{F}=.632$, $\mathrm{p}>0.05)$.

A MANOVA was then run to investigate the differences between the use of each SS category by left brained, right brained and whole brained learners. Preliminary assumption testing was performed to check for normality, multicollinearity, linearity, homogeneity of variance covariance matrices, and univariate and multivariate outliers, with no serious violations noted. Table 2 illustrates the statistically significant differences found between left-, right-, and whole brained students on the combined dependent variables, $F(8,272)=2.249$, p = .024; Wilks' Lambda $=.88$; partial eta squared $=.062$.

Table 2. Multivariate tests for the effect of brain dominance on different categories of SS

\begin{tabular}{lcccccc}
\hline Effect & value & F & hypothesis df & Error df & Sig. & D \\
\hline Wilks'Lambda & .880 & 2.249 & 8.000 & 272.000 & $.024^{*}$ & .062 \\
\hline
\end{tabular}

To find out where the differences lied, tests of between-subjects effects were run. As shown in table 3 , these differences belonged to compensation SSs $(\mathrm{p}=.01)$.

Table 3. Tests of between-subjects effects for the effect of hemisphericity on different categories of SS

\begin{tabular}{llllllll}
\hline Source & Dependent Variable & Type III Sum of Squares & df & Mean Square & F & Sig. & D \\
\hline \multirow{4}{*}{ BD } & metacognitive & 124.570 & 2 & 62.285 & 1.122 & .328 & .016 \\
\cline { 2 - 7 } & cognitive & 1.001 & 2 & .500 & .036 & .965 & .001 \\
\cline { 2 - 7 } & memory/socio-affective & 44.401 & 2 & 22.201 & 1.016 & .365 & .014 \\
\cline { 2 - 7 } & compensation & 45.537 & 22.769 & 4.785 & $.010^{*}$ & .064 \\
\hline
\end{tabular}

To investigate which brain orientation used compensation SSs more frequently, a one way between-groups ANOVA was run.

Table 4. Results of post hoc test for the effect of brain dominance on different categories of SS

(I) BD (J) BD Mean Difference (I-J) SD Sig.

\begin{tabular}{lllll}
\hline \multirow{2}{*}{ right } & left & .19063 & .41174 & .889 \\
\cline { 2 - 5 } & whole & $-1.32366^{*}$ & .49427 & .022 \\
\hline \multirow{2}{*}{ left } & right & -.19063 & .41174 & .889 \\
\cline { 2 - 5 } & whole & $-1.51429^{*}$ & .51490 & .011 \\
\hline \multirow{2}{*}{ whole } & right & $1.32366^{*}$ & .49427 & .022 \\
\cline { 2 - 5 } & left & $1.51429^{*}$ & .51490 & .011 \\
\hline
\end{tabular}

A statistically significant difference was found between the whole brain dominant participants and both left brain and right brain dominant learners for using these strategies.

\section{Discussions}

With respect to the general pattern of brain dominance of Shiraz University undergraduate students, no significant difference was found between left-, right- and whole-brain students in their use of speaking strategies. Consequently, it can be concluded that hemisphericity did not have much influence on the overall SS use. The results obtained by Kucuk (2012) for undergraduate Turkish EFL learners, and Naimie, Abuzaid, Siraj, Shagholi, and Al Hejaili (2010) for Iranian English-major university students, too, indicated no difference between different continuums of learning styles and use of LLSs. They proposed that learners might have chosen the language learning strategies that facilitated learning tasks that helped them become better language learners, rather than relying merely on their learning style. Based on Ehrman and Oxford (1989), field of specialization has a strong effect on LLS use, the similarity of the results may be due to the field of specialization, EFL, which is the same in these studies.

With respect to categories of SS, however, a significant difference was found between whole brain dominant students and right and left brain dominant ones regarding their use of compensatory SS. In line with this finding, Salehi and Bagheri (2011), Nikoopour and Farsani (2010), and Jhaish (2010) significantly related specific learning styles to some specific LLSs. Nikoopour and Farsani (2010) found relationships between students' learning styles and their use of compensation strategies. Furthermore, Jhaish (2010) found positive correlations between memory strategies with the kinesthetic style on the one hand and group learning style with compensation strategies on the other. Salehi and Bagheri (2011) also found significant relationships between kinesthetic styles and the use of compensation strategies. They believed that kinesthetic learners were able to guess intelligently by making use of either linguistic or non-linguistic clues. 
In our case, these significant differences can be related to the fact that compensatory strategies equip students with necessary techniques to comprehend and produce language in spite of their limited language knowledge. This means that learners have the ability to guess intelligently by making use of both linguistic and non-linguistic clues. Brown (2007) has also indicated that although language functions appear to be controlled in the left hemisphere, there is a significant right hemisphere participation which consists of strategies of acquisition. Strategies such as guessing at meanings and using formulaic utterances, are considered as examples of right hemisphere activity (Olber, 1981). Since speaking is both verbal and non-verbal and compensatory speaking strategies are a combination of both verbal and nonverbal strategies, it might be that whole brain dominant students used these strategies more than the other two groups because they were capable of using both verbal and nonverbal behaviors at the same time.

This result also supports Yeap's (1989) claim that neither left nor right hemisphere users are better or worse than the other and their differences are just rooted in the types of incoming information. In other words, the use of left and right hemispheres are equally valid methods of acting, processing, perceiving and storing information which complete each other's functions.

\section{Conclusion}

Considering individual differences and their effect on the learning process, instructors and learners must combine activities that accommodate both left and right brain learners. Based on Jhaish (2010), considering the students' learning style and balancing their instruction by making use of a wide variety of tasks in the classroom, teachers can achieve success in this regard. Therefore, considering students' brain dominance, teachers must not only make use of verbal, linear models, but also active, image-rich, visual-spatial models so that learners would be able to use both hemispheres.

Since the findings of the present study yield significant differences between the learners with different brain dominant in their use of compensation strategies, it is suggested that teachers explicitly instruct students on the use of strategies such as guessing meanings and using formulaic utterances and encourage students to use both verbal and nonverbal strategies and provide opportunities for their learners to practice these strategies.

\section{References}

Afsarnia, M. (1999). EFL strategy inventory for listening comprehension, its psychometric characteristics, factor analysis, and the intermediate effects of gender, proficiency level, LC strategies, and LC scores in authentic LC texts and tasks. Unpublished MA thesis, Shiraz University, Shiraz, Iran.

Alavi, S., \& Mireskandarin, N. (2014). Brain dominance and listening comprehension strategy use of Iranian EFL learners. Journal of Language and Literature, 6 (1), http://www.ijar.lit.az/philology.php?go=currentjll

Alptekin, C., \& Atakan, S. (1990). Field dependence-independence and hemisphericity as variables in L2 achievement. Second Language Research, 6 (2), 135-149.

Beck, C. R. (2001). Matching teaching strategies to learning style preferences. The Teacher Educator, 37 (1), 1-15.

Bialystok, E., \& Frölich, M. (1980). Oral communication strategies for lexical difficulties. Interlanguage Studies Bulletin, 5, 3-30.

Brown, H. D. (2007). Principles of language learning and teaching $\left(5^{\text {th }}\right.$ ed.). New York: Pearson Education.

Chen, S. Q. (1990). A study of communication strategies in interlanguage production by Chinese EFL learners. Language Learning, 40 (2), 155-187.

Davis, E.C., Nur, H., \& Ruru, S.A.A. (1994). Helping teachers and students understand learning styles. English Teaching Forum, 32 (3), 12-38.

Dulger, O. (2012). Brain dominance and language learning strategy usage of Turkish EFL learners. Cognitive Philology, 5, 1-23.

Dorney, S., \& Scott, M. L. (1997). Communication strategies in a second language: Definitions and taxonomies. Language Learning, 47, 173-210.

Ehrman, M. L., \& Oxford, R. L. (1989). Effects of sex differences, career choice, and psychological type on adult language learning strategies. Modern Language Journal, 73 (1), 1-13.

Faerch, C., \& Kasper, G. (1983). Strategies in inter-language communication. London, United Kingdom: Longman.

Gholami Mehrdad, A., \& Ahghar, M. (2011). Learning styles and learning strategies of left-handed EFL students. Procedia - Social and Behavioral Sciences, 31, 536 - 545.

Gibson, K. M. (2002). Learning styles and hemispheric dominance- right or left brain: Which is dominant in your family? Home, education learning magazine. Retrieved May, 22, 2014, from http://www.leapingfromthebox.com/art/kmg/learningstyles2

Green, J., \& Oxford, R. L. (1995). A closer look at learning strategies, L2 proficiency, and gender. TESOL Quarterly, 29, 261-297.

Huang, C. P. (2010). Exploring factors affecting the use of oral communication strategies. Luangwa university journal, 12(1), 85-104.

Huang, X. H., \& Van Naerssen, M. (1987). Learning strategies for oral communication. Applied Linguistics, 8, 287307. 
Jhaish, M. A. (2010). The relationship among learning styles, language learning strategies, and the academic achievement among the English majors at Al-Aqsa University. MA thesis, The Islamic University, Gaza.

Afsarnia, M. (1999). EFL strategy inventory for listening comprehension, its psychometric characteristics, factor analysis, and the intermediate effects of gender, proficiency level, LC strategies, and LC scores in authentic LC texts and tasks. Unpublished MA thesis, Shiraz University, Shiraz, Iran.

Alavi, S., \& Mireskandarin, N. (2014). Brain dominance and listening comprehension strategy use of Iranian EFL learners. Journal of Language and Literature, 6 (1), http://www.ijar.lit.az/philology.php?go=currentjll

Alptekin, C., \& Atakan, S. (1990). Field dependence-independence and hemisphericity as variables in L2 achievement. Second Language Research, 6 (2), 135-149.

Beck, C. R. (2001). Matching teaching strategies to learning style preferences. The Teacher Educator, 37 (1), 1-15.

Bialystok, E., \& Frölich, M. (1980). Oral communication strategies for lexical difficulties. Interlanguage Studies Bulletin, 5, 3-30.

Brown, H. D. (2007). Principles of language learning and teaching $\left(5^{\text {th }}\right.$ ed.). New York: Pearson Education.

Cesur, M. O., \& Fer, S. (2011). A model explaining relationship between language learning strategies, learning styles and success in reading comprehension. Journal of Education, 41, 83-93.

Chen, S. Q. (1990). A study of communication strategies in interlanguage production by Chinese EFL learners. Language Learning, 40 (2), 155-187.

Davis, E.C., Nur, H., \& Ruru, S.A.A. (1994). Helping teachers and students understand learning styles. English Teaching Forum, 32 (3), 12-38.

Dulger, O. (2012). Brain dominance and language learning strategy usage of Turkish EFL learners. Cognitive Philology, 5, 1-23.

Dorney, S., \& Scott, M. L. (1997). Communication strategies in a second language: Definitions and taxonomies. Language Learning, 47, 173-210.

Ehrman, M. L., \& Oxford, R. L. (1989). Effects of sex differences, career choice, and psychological type on adult language learning strategies. Modern Language Journal, 73 (1), 1-13.

Faerch, C., \& Kasper, G. (1983). Strategies in inter-language communication. London, United Kingdom: Longman.

Gholami Mehrdad, A., \& Ahghar, M. (2011). Learning styles and learning strategies of left-handed EFL students. Procedia - Social and Behavioral Sciences, 31, 536 - 545.

Gibson, K. M. (2002). Learning styles and hemispheric dominance- right or left brain: Which is dominant in your family? Home, education learning magazine. Retrieved May, 22, 2014, from $\mathrm{http}: / / \mathrm{www}$.leapingfromthebox.com/art/kmg/learningstyles2

Green, J., \& Oxford, R. L. (1995). A closer look at learning strategies, L2 proficiency, and gender. TESOL Quarterly, 29, 261-297.

Huang, C. P. (2010). Exploring factors affecting the use of oral communication strategies. Luangwa university journal, 12(1), 85-104.

Huang, X. H., \& Van Naerssen, M. (1987). Learning strategies for oral communication. Applied Linguistics, 8, 287307.

Jhaish, M. A. (2010). The relationship among learning styles, language learning strategies, and the academic achievement among the English majors at Al-Aqsa University. MA thesis, The Islamic University, Gaza.

Jie, L., \& Xiaoquing, Q. (2006). Language learning styles and learning strategies of tertiary level English learners in China. RELC, 37(1), 67-90.

Keith, R. (2010). Building blocks in the foreign language classroom. Revista Electronica Actualidades Investigation en Education, 10(3), 1-36.

Kucuk, M. (2012). The relationship between online learners' learning styles and learning strategies. H. U. Journal of Education, 42, 287-298.

Lee, C. K. (2010). An overview of language learning strategies. ARECLS, 7, 132-152.

Leng, Y. L., \& Hoo, C. T. (1997). Explaining the thinking, learning styles and cognition constructs. The Mathematics Educator, 2(1), 113-127.

Littlemore. J. (2001). An empirical study of the relationship between cognitive style and the use of communication strategy. Applied Linguistics, 22(2), 241-265.

Naimie, Z., Abuzaid, R. A., Siraj, S., Shagholi, R., \& Al Hejaili, H. (2010). Do you know where I can find the new center which is called cognitive styles and language learning strategies link? Procedia Social Behavioral Sciences, 2 , 497-500.

Nakatani, Y. (2005). The effects of awareness-raising training on oral communication strategy use. Modern Language Journal, 89, 76-91.

Nakatani, Y. (2006). Developing an oral communication strategy inventory. Modern Language Journal, 90, 151-168.

Nakatani, Y. (2010). Identifying strategies that facilitate EFL learners' oral communication: A classroom study using multiple data collection procedures. Modern language Journal, 94, 116-136.

Nikoopour, J., \& Farsani, M. A. (2010). On the relationship between language learning strategies and personality types 
among Iranian EFL learners. Journal of English Studies, 1(1), 81-101.

Oflaz, M. (2011). The effect of right and left brain dominance in language learning. Procedia Social and Behavioral Sciences, 15,1507-1513.

Obler, L. (1981). Right hemisphere participation in second language acquisition. In K. Diller, (Ed.), Individual Differences and Universals in Language Learning Aptitude. Rowley, MA: Newbury House.

O’Malley, J. M., \& Chamot, A. U. (1990). Learning strategies in second language acquisition. London: Cambridge University Press.

O'Malley, J. M., Chamot, A. U., Stewner-Manzanares, G., Kupper, L. J., \& Russo, R. P. (1985). Learning strategies used by beginning and intermediate ESL students. Language Learning, 35(1), 21-36.

Oxford, R. L. (1990). Language learning strategies: What every teacher should know. New York: Newbury House Publishers.

Oxford, R. L. (2003). Language learning styles and strategies: Concepts and relationships. IRAL, 41(4), 271-278.

Oxford, R.L., \& Ehrman, M.E., (1995). Adults' language learning strategies in an intensive foreign language program in the United States. System, 23, 359-386.

Paribakht, T. (1985). Strategic competence and language proficiency. Applied Linguistic, 6(2), 132-145.

Poiltzer, R. (1983). Research notes: An exploratory study of self-reported language learning behaviors and their relation to achievement. Studies in Second Language Acquisition, 6, 54-68.

Politzer, R., \& McGroarty, M. (1985). An exploratory study of learning behaviors and their relationship to gains in linguistic and communicative competence. TESOL Quarterly, 9(1), 103-120.

Riazi, A. M., \& Khodadadi, F. (2007). The effect of EFL students' level of proficiency and gender on the use of speaking strategies. TELL, 1, 99-116.

Sabatin, I. (2012). Learning strategies: Perceptual styles and brain hemisphericity. Athens: ATINERS conference Paper Series, NO: LIT2012-0230.

Salehi, M., \& Bagheri, M.S. (2011). The relationship between Reid's learning styles and Oxford's language learning strategies in adult EFL learners of Iran Language Institute. Iranian EFL Journal, 7(4), 120-140.

Sedaghat, M. (2001). The effects of attitude, motivation (instrumental and integrative), and proficiency level on the use of listening comprehension strategies by Iranian female EFL students. Unpublished master's thesis, Shiraz University, Shiraz.

Selime, T. (2003). The relationship between learning styles and language learning strategies of pre-intermediate EAP students. Master's thesis, Middle East Technical University.

Shi, C. (2011). A study of the relationship between cognitive styles and learning strategies. Higher Education Studies, 1(1), 20-26.

Shih, C. C., \& Gamon, J. A. (2002). Relationships among learning strategies, patterns, styles, and achievement in webbased course. Journal of Agricultural Education,43(4), 1-11.

Soodbakhsh, N. (2009). An investigation into the nature of oral communication strategies used by Iranian EFL learners: The effect of level of oral proficiency, motivation and attitude. Unpublished MA thesis, Shiraz University, Shiraz, Iran.

Souzandehfar, M. (2009). Variables predicting English oral proficiency among Iranian EFL students. Unpublished MA thesis, Shiraz University, Shiraz, Iran.

Tendero, J.B. (2008). Hemispheric dominance and language proficiency in the four macro skills of the western Mindanao state university college students. Unpublished doctorial dissertation, Western Mindanao State University, Philippines.

Tremblay,T., Monetta,L., \& Joanette,Y. (2004). Phonological processing of words in right- and left-handers. Brain and Cognition 55, 427-432.

Tufekci, S., \& Demirel, M. (2008). The effect of brain based learning on achievement, retention, attitude and learning process. Procedia Social and Behavioral Sciences, 1, 1782-1791.

Wang, T.L. (2008). Brain hemispheric preferences of fourth-and fifth-grade science teachers and students in Taiwan: An investigation of the relationships to student spatial and verbal ability, student achievement, student attitudes, and teaching practice. Doctoral Dissertation, School of the Ohio State University, USA.: UMI company

Wong, L. C., \& Nunan, D. (2011). The learning styles and strategies of effective language learners. System, 39, 144163.

Yeap, L. L. (1989). Hemisphericity and student achievement. Neuroscience, 48, 225-235.

Yilmaz-Soylu, M., \& Akkoyunlu, B. (2002). The effect of learning styles on achievement in different learning environments. The Turkish Online Journal of Educational Technology, 8 (4), 1303-6521. 